\title{
PLANEJAMENTO DA PAISAGEM COMO INSTRUMENTO PROMOTOR DA SUSTENTABILIDADE URBANA
}

\author{
Sandra Medina Benini ${ }^{1}$
}

Resumo: Este artigo propõe uma reflexão sobre o planejamento da paisagem como um instrumento promotor da sustentabilidade urbana. Para desenvolvimento do texto partiu-se de um levantamento conceitual de paisagem, indo para uma discussão sobre a construção da sustentabilidade urbana e o planejamento da paisagem como uma possibilidade de intervenção urbana. Como procedimento metodológico adotouse uma pesquisa qualitativa sobre a proposta, onde consistiu no exame da literatura pertinente de trabalhos científicos (livros, teses, dissertações, artigos, etc.).

Palavras Chave: Paisagem. Estatuto da Cidade. Sustentabilidade Urbana.

\section{CONSIDERAÇÕES SOBRE O CONCEITO DE PAISAGEM}

Considera-se que a "paisagem é resultado do equilíbrio entre múltiplas forças e processos temporais e espaciais" (LEITE, 1994, p. 7). Para Macedo (1999, p.11), a "paisagem é como a expressão morfológica das diferentes formas de ocupação, portanto, de transformações do ambiente em um determinado tempo".

Leite $(1994$, p. 7) esclarece que a paisagem "é um reflexo da visão social do sistema produtivo e suas formas transformam-se ou desaparecem sempre que as teorias, filosofias e necessidades que as criaram não são mais reais ou autoevidentes". Neste sentido, Macedo (1999, p. 11) considera que a paisagem "como um produto e como um sistema. Como produto porque resulta de um processo social de ocupação e gestão de determinado território. Como um sistema, na medida em que, a partir de qualquer ação sobre ela impressa", deste modo "haverá uma

\footnotetext{
${ }^{1}$ Doutoranda no Programa de Pós-Graduação em Geografia da UNESP - Univ Estadual Paulista, Presidente Prudente. E-mail: sandra@sigmaambiente.com
} 


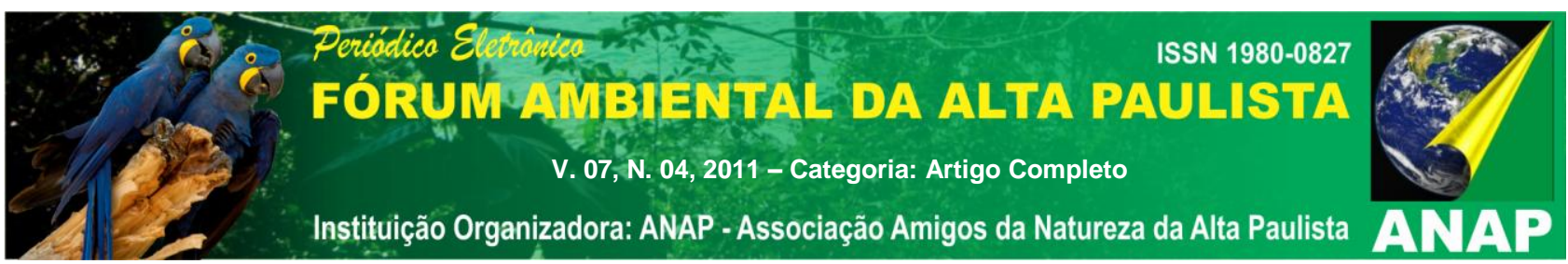

reação correspondente, que equivale ao surgimento de uma alteração morfológica parcial ou total".

No tocante aos elementos que compõem uma paisagem, Leite (1994) explica que

[...] muitos lugares e elementos que compõem uma paisagem são atribuídos valores específicos que mudam constantemente acompanhando a evolução dos padrões culturais. Estes estão, por sua vez, fortemente enraizados nos processos naturais de cada lugar ou região, isto é, a natureza e a cultura juntas, como processos integrantes, conferem forma e individualidade aos lugares. Os ritmos climáticos, hidrológico e biológico para moldar uma paisagem cujos padrões de produção e utilização variam de acordo com o contexto específico da sociedade. (LEITE, 1994, p. 7)

Complementando as proposituras de Leite (1994), Macedo explica que no recorde analítico da paisagem, em dado lugar, é possível atribuir três tipos de qualidades:

1. ambiental - que mede as possibilidades de vida e sobrevida de todos os seres vivos e das comunidades na paisagem existentes;

2. funcional - que avalia o grau de eficiência do lugar no tocante ao funcionamento da sociedade humana.

3. estética - que apresenta valores com características puramente sociais, atribuídas pelas comunidades humanas a algum lugar, em um momento do tempo. (LEITE, 1994, p. 13)

Neste enfoque, pode-se dizer que "toda paisagem está ligada a uma ótica de percepção humana, a um ponto de vista social e que sempre representa total ou parcialmente um ambiente" (MACEDO, 1999, p. 11). Nesta mesma lógica, Leite (1994) complementa afirmando que

Uma paisagem modificada pelo homem não é, portanto, uma paisagem antinatural, mas uma paisagem cultural que deve atender tanto a critérios funcionais quanto estéticos. Assim sendo, não pode ser planejada de acordo apenas com prioridades econômicas rigorosas que levam à perda dos valores ambientais para posteriormente, ser embelezada, num ato de redenção estética pela inserção de elementos românticos pseudonaturais. (LEITE, 1999, p. 7) 


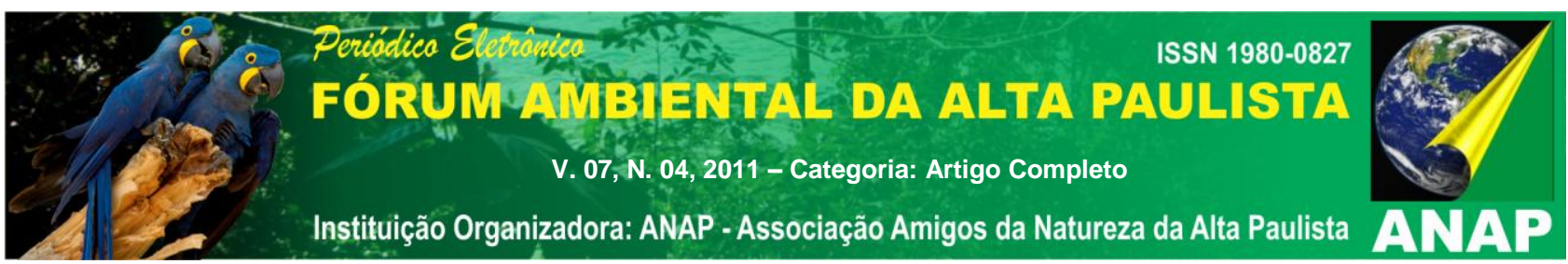

Para não incidir nos equívocos do planejamento, apontados por Leite (1994), Macedo (1999) esclarece que o planejamento da paisagem deve considerar:

a) as características funcionais de suporte físico, tanto do solo como do subsolo, suas redes de drenagem, os aqüíferos e suas suscetibilidade perante a ação antrópica;

b) as características climáticas do lugar e as diferentes formas e possibilidades de adaptação das comunidades de seres vivos a essas características;

c) as características dos ecossistemas existentes - suas formas principais de vida e seu valor no contexto do lugar e do país, além de seu potencial de aproveitamento, em termos de recursos, para a sociedade humana;

d) os valores sociais, e portanto culturais, atribuídos ao local e suas implicações na sobrevivência das diferentes formas de comportamento social;

e) os padrões de ocupação antrópicas - tanto urbana quanto rural, seu porte, dimensionamento, tendências e possibilidades de expansão e suas formas de relacionamento com estruturas de suporte físico e ecossistemas existentes e seus agentes formadores;

f) o grau de processamento das estruturas ambientais existentes e a conveniência de sua transformação a médio e curto prazo, isto é, a mensuração dos níveis de transformação das diversas estruturas ambientais de cada área, seu potencial de utilização e de sobrevida perante um processo de uso, exploração e ocupação humana. 0 objetivo, no caso, é avaliar o real estoque de recursos ambientais, seus níveis de produtividades e a sua capacidade de absorção e recuperação diante das diferentes formas de exploração;

g) as características dos elementos componentes das estruturas morfológicas da paisagem (que seja o suporte físico ou a vegetação), as diferentes formas de ocupação humana: cidades, campos, industrias, estradas e águas. Neste sentido, o fator de excepcionalidade em relação um determinado referencial escalar deve ser considerado, e tanto maior será valor paisagístico desse ou daqueles, como um país, um estado, um setor ou um pequeno segmento do território. Os padrões culturais vigentes, que são extremamente variáveis dentro da sociedade, no espaço e no tempo, também devem ser considerados." (MACEDO, 1999, p. 13)

Todavia, Macedo (1999, p. 13) alerta que as "ideias sobre paisagem são diretamente vinculadas aos conceitos de habitat e principalmente de espaço. Cada paisagem contém espaços, lugares onde vivem comunidades inteiras, podendo conter partes ou todos de ecossistemas diversos".

\section{CONSTRUÇÃO DA SUSTENTABILIADE URBANA}




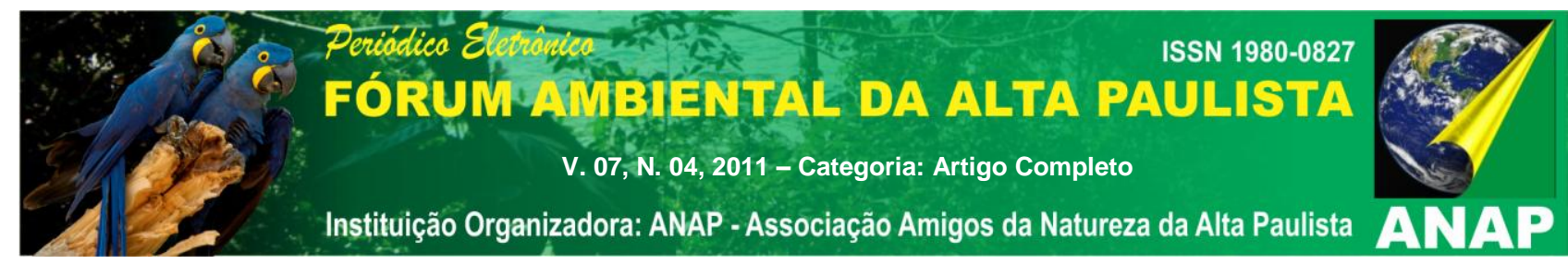

Para dar início a discussão de sustentabilidade urbana, parte-se dos estudos de Rogers (2001, p.155) que sustentabilidade ${ }^{2}$ também pode ser considerada como "uma nova ordem de eficiência econômica, que beneficia a todos os cidadãos, em vez de beneficiar alguns poucos em detrimento de muitos".

A noção da sustentabilidade urbana surge como forma de conjugação da questão econômica, social, política, cultural e ambiental, onde haja o comprometimento com processos de urbanização e práticas urbanísticas que incorporem a dimensão sócio-ambiental na produção e na gestão do espaço. Todavia, Acselrad (2001) alerta que matérias relacionadas à sustentabilidade ${ }^{3}$ devem ser articuladas com um discurso ético.

A sustentabilidade é também articulada por um discurso da ética, que elabora a conduta humana diante dos valores construídos de bem e de mal. Destacam-se aqui as intenções das ações que têm por objeto uma base material biofisicamente comum, interligando espaços, homens e tempos. (ACSELRAD, 2001, p. 35).

Neste sentido, a "pauta da sustentabilidade passou a indicar os contornos de políticas urbanas, tendo sido transposta para a esfera política no contexto do papel estratégico que assumem as cidades no período de globalização da economia, fundamentando" (MARCONDES, 1999, p. 38).

A proposta de uma sustentabilidade urbana vem de encontro com o princípio do desenvolvimento sustentável, o qual tem por objetivo atender as "necessidades do presente sem comprometer a possibilidade das gerações futuras atenderem a

\footnotetext{
${ }^{2}$ Dever-se-ia falar de sociedade sustentável ou de planeta sustentável ao invés de pré-condições indispensáveis para um desenvolvimento verdadeiramente integral. Sustentável é a sociedade ou o planeta que produz o suficiente para si para os seres dos ecossistemas onde ela se situa; que toma da natureza somente o que ela pode repor; que mostra um sentido de solidariedade generacional, ao preservar para as sociedades futuras os recursos naturais de que elas precisarão. Na prática a sociedade deve mostrar-se capaz de assumir novos hábitos e de projetar um tipo de desenvolvimento que cultive o cuidado com os equilíbrios ecológicos e funcione dentro dos limites impostos pela natureza. Não significa voltar ao passado, mas oferecer um novo enfoque para o futuro comum. Não se trata simplesmente de não consumir, mas de consumir responsavelmente (BOFF, 1999. p. 137)

${ }^{3}$ Por um lado, se a sustentabilidade é vista como algo bom, desejável, consensual, a definição que prevalecer vai construir autoridade para que se discriminem, em seu nome, as boas práticas, das ruins. Abre-se, portanto, uma luta simbólica pelo reconhecimento da autoridade para falar em sustentabilidade. (ACSELRAD, 2001, p. 29).
} 
suas próprias necessidades" (CMMAD, 1988, p.46). Neste sentido, Acselrad (2001) complementa que

A associação da noção de sustentabilidade com 0 debate sobre desenvolvimento das cidades tem origem nas rearticulações políticas pelas quais um certo número de atores envolvidos na produção do espaço urbano procuram dar legitimidade às suas perspectivas, evidenciando a compatibilidade das mesmas com os propósitos de dar durabilidade ao desenvolvimento, em acordo com os princípios da Agenda 21, resultante da Conferência da ONU sobre Desenvolvimento e Meio Ambiente. (ACSELRAD, 2001, p. 36 - 37).

Para Acselrad (1999) a sustentabilidade urbana está estritamente relacionada com a qualidade gestão, considerando pólos distintos:

[...] de um lado, aquele que privilegia uma representação técnica das cidades pela articulação da noção de sustentabilidade urbana aos modos de gestão dos fluxos de energia e materiais associados ao crescimento urbano; de outro, aquele que define a insustentabilidade das cidades pela queda da produtividade dos investimentos urbanos, ou seja, pela incapacidade destes últimos acompanharem o ritmo de crescimento das demandas sociais, o que coloca em jogo, o espaço urbano como território político. (ACSELRAD, 1999, p. 79)

Para equacionar estes pólos e obtermos a sustentabilidade urbana, parte-se do pressuposto da necessidade da aplicação de modelos de planejamento ${ }^{4}$ do espaço urbano, considerado a inter-relação entre dimensões sociais, econômicas e ambientais para a realização de uma gestão eficiente. Grostein (2001) complementa Acselrad (1999) ao explicar que as dinâmicas presentes no processo de urbanização, as quais colocam em xeque a sustentabilidade urbana.

O avanço do processo de urbanização, sua escala e velocidade, não constituem problema em si, não fosse o modo como ocorreu. A ele devemos estar atentos, pois a sustentabilidade do aglomerado urbano/metropolitano, em sua componente físico-urbanística, relaciona-se com as seguintes variáveis: a forma de ocupar o território, a disponibilidade de insumos para seu funcionamento (disponibilidade de água), a descarga de resíduos (destino e tratamento de esgoto e lixo); o grau de mobilidade da população no espaço urbano (qualidade do transporte público de massa); a oferta e 0 atendimento às necessidades da população por moradia,

\footnotetext{
${ }^{4}$ Conforme ensina Souza (2002, p. 46), "planejar significar prever a evolução de um fenômeno [...]. Planejamento é a preparação para gestão futura, buscando evitar ou minimizar problemas e ampliar as margens de manobra".
} 


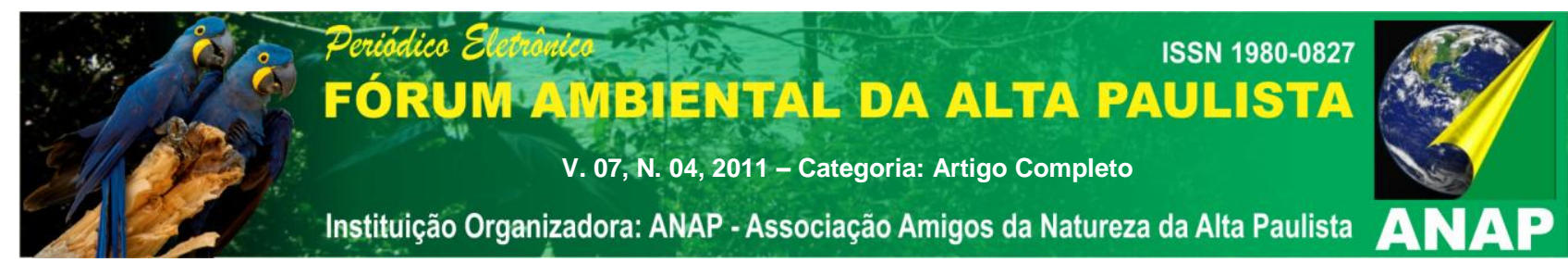

equipamentos sociais e serviços e a qualidade dos espaços públicos. Assim sendo, as políticas que os sustentam o parcelamento, uso e ocupação do solo e as práticas urbanísticas que viabilizam estas ações, tem papel efetivo na meta de conduzir as cidades no percurso do desenvolvimento sustentado. (GROSTEIN, 2001, p. 20)

No Brasil, devido a um cenário de luta pela reforma urbana, a Constituição Federal de 1988 reservou um capítulo para tratar da Política Urbana (art. 182 e 183) que posteriormente foi regulamentado pela Lei 10.257, de 10 de julho de 2001. Esta lei denominada de Estatuto da Cidade, é instrumento jurídico que contempla normas de ordem pública e interesse social, tendo entre as suas principais premissas, a função social da propriedade urbana. Entretanto, Santos (2004) esclarece que

\begin{abstract}
Nesse cenário de luta, pela reforma urbana e pela redistribuição e democratização das melhores vantagens comparativas no e do urbano, novamente 0 ambiente e a paisagem são relegados a um segundo plano. As questões de paisagem nesse contexto circunscrevem-se: ao projeto dos parques urbanos, à recuperação de umas poucas áreas de mananciais, e em alguns dos projetos "re" nas áreas centrais. Os procedimentos conservadores se confirmam e explicita-se a incompreensão do papel que os aspectos de paisagem e ambiente podem ter no processo de planejamento. (SANTOS, 2004, p. 04)
\end{abstract}

Pellegrino (2000, p. 171) complementa as proposituras de Santos (2004), esclarecendo que os desafios "constantes no planejamento, projeto e manejo de uma área não se resumem em se ter uma visão espacial e temporal de uma ampla área, mas em se enfrentar as principais questões sociais e ambientais presentes".

Neste sentido, o Estatuto da Cidade define quais são os instrumentos (planejamento, jurídicos, políticos, tributários e financeiros) que o Poder Público, especialmente o Município, deve utilizar para enfrentar os problemas de desigualdade social e territorial nas cidades, bem como, pode ser considerado como um instrumento de proteção do ambiente urbano, na medida em que estabelece uma série de diretrizes e mecanismos para que venha alicerçar o planejamento da paisagem. 


\section{PLANEJAMENTO DA PAISAGEM COMO UMA POSSIBILIDADE DE INTERVENÇÃO URBANA}

Pellegrino (2000, p. 171) destaca que os "desafios constantes no planejamento, projeto e manejo de uma área não se resumem em se ter uma visão espacial e temporal de uma ampla área, mas em se enfrentar as principais questões sociais e ambientais presentes", e esclarece que

[...] abastecimento de água, transporte e circulação, biodiversidade, recursos paisagísticos, relações culturais e comunitárias, agricultura entre outros tantos mais, são fatores essenciais a serem considerados. Para que todos os planos atendam adequadamente a essas questões, uma ampla gama de conhecimentos técnicos específicos deve ser alcançada. (PELEGRINO, 2000, p. 171)

Apesar das proposituras de Pellegrino (2000), Queiroga (1994, p. 223) destaca que o "planejamento urbano no país foi profundamente marcado pela ideologia funcionalista do urbanismo moderno, tradicionalmente, pouca atenção dá à paisagem e ao ambiente urbano." Neste sentido, Ruano (1999, p.18) esclarece que o "planejamento estão baseados na insuficiência dos espaços públicos, na carência da escala humana, na escassez de lugares para interação social, na baixa densidade, na ênfase excessiva da separação, no individualismo", numa lógica de "auto-proteção, na zonificação funcional demasiada, etc, são uma das principais causas da perda da qualidade urbana".

Neste contexto, Ruano (1999, p. 12) propõe como alternativa a estas demandas urbanas, a necessidade se adotar um planejamento que tenha como "base na sustentabilidade e na qualidade de vida de nossas cidades, através da análise, organização e do bom funcionamento dos seguintes aspectos: mobilidade urbana, recursos, participação, comunidade, eco-turismo," etc..

Dentre as demandas elencadas por Ruano (1999), Leite (1994, p. 90) destaca que "participação popular" é um instrumento estratégico à "adoção da experiência e da percepção como instrumento dessa participação permitiriam a formação de paisagens originadas de condições regionais e locais de trabalho e 
 \\ V. 07, N. 04, 2011 - Categoria: Artigo Completo \\ Instituição Organizadora: ANAP - Associação Amigos da Natureza da Alta Paulista}

cends.

vida", como alternativa aos modelos preconcebidos resultantes da imposição a sociedade.

Leite (1994, p. 90) destaca que o "modelo do desenvolvimento adotado no Brasil penalizou a natureza e a sociedade", visto que é recorrente a "visão da paisagem como o cenário que recebe as determinações por ele imposta, cria, ainda hoje, enormes dificuldades em aceita-la como base para a formulação dessas determinações", bem como, dos "objetivos tão diferentes entre as regiões mais e menos desenvolvidas do País". Neste sentido, Pellegrino (2003) alerta que

[...] de um lado, em uma desvalorização da paisagem, e, de outro, em uma crescente alienação da dimensão ambiental do espaço urbano, trazendo como conseqüência a impossibilidade de pensar o espaço - e o ambiente como totalidades, ainda que abertas e carregadas de conflito. Como resultado, difunde-se uma apatia generalizada entre seus habitantes para com a deterioração dos espaços de seu cotidiano, e, como produto, temos uma realidade urbana que se torna feia, agressiva e insegura, que reflete uma sociedade impotente no enfrentamento de questões sócio-ambientais. (PELLEGRINO, 2003, p. 02)

Diante deste contexto é "inegável que a organização do território brasileiro atinge, atualmente, os mais altos níveis de especialização regional, com concentração de atividades industriais, comerciais e habitacionais em algumas áreas superlotadas" (LEITE, 1994, p. 88).

Leite (1994, p. 88) esclarece que cada vez mais "distantes a possibilidade de reorganizar o território sem repensar o modelo econômico, a localização das atividades industriais, os tipos de urbanização, a função dos espaços não urbanizados, as necessidades específicas dos grupos sociais". Neste sentido, a autora (LEITE, 1999) alerta que a construção da paisagem

[...] dentro das regras do jogo de relações que favoreça uma maior diversidade de estilos de vida, implica, exatamente, enfrentar as contradições do capitalismo, entender o conflito entre as inovações e o estabelecido. Isso só pode ser feito baseando-se na compreensão dos processos, naturais ou não, que levem ao exaurimento ou à degradação da paisagem, simultaneamente com a compreensão das razões sociais, econômicas e políticas que levam à adoção de determinadas práticas de utilização do território. Em essência, implica entender resultantes das condições gerais de evolução da sociedade; tal entendimento pode ser alcançado a partir, por exemplo, das 'desigualdades' da paisagem. (LEITE, 1999, p. 88) 
Deste modo, o planejamento deve ser entendido como um instrumento mitigador dos processos de exaurimento e degradação da paisagem. Assim, faz se necessário pensar o planejamento da paisagem como uma ferramenta capaz da promoção da sustentabilidade urbana.

\section{CONSIDERAÇÕES PARCIAIS}

O conceito de paisagem pode ser compreendido pela equação de forças e processos temporais, sociais e espaciais, as quais são responsáveis pelas transformações do ambiente. Deste modo, devido as dinâmicas presentes no processo de construção da paisagem faz se necessário pensar num modelo de planejamento capaz da promoção da sustentabilidade urbana.

Neste sentido, indica-se o Estatuto da Cidade para enfrentar os problemas de desigualdade social e territorial nas cidades, bem como, para proteção da paisagem urbana, visto que este é um instrumento de planejamento capaz de promover da sustentabilidade urbana.

\section{REFERENCIAL}

ACSELRAD, Henri. Discursos da Sustentabilidade Urbana. Revista Brasileira de Estudos Urbanos e Regionais, Campinas: no 01, maio/ 1999.

. Sentidos da sustentabilidade urbana. In: ACSELRAD, Henri (Org.). A duração das cidades: sustentabilidade e risco nas políticas urbanas. Rio de Janeiro: DP\&A, 2001. p. 27-55.

BRASIL. Constituição (1988). Constituição da República Federativa do Brasil: promulgada em 05 de outubro de 1988. São Paulo: Revista dos Tribunais, 2009. 


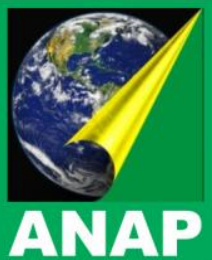

. Lei Federal ํㅜ 10.257 (2001). Estatuto da Cidade. DOU 11.07.2001, ret. DOU 17.07.2001.

CMMAD - Comissão Mundial sobre Meio Ambiente e Desenvolvimento. Nosso futuro comum. Rio de Janeiro: FGV, 1988.

GROSTEIN, M. D. Metrópole e Expansão Urbana: a Persistência de Processos “Insustentáveis". São Paulo em Perspectiva. Fundação SEADE. Nº 01, 2001.

LEITE, Maria Angela Faggin Pereira. Destruição ou desconstrução? Ed. Hucitec: São Paulo, 1994.

MACEDO, Silvio Soares. Quadro do Paisagismo no Brasil. São Paulo, 1999, 144 p.

MARCONDES, M. J. A. Cidade e Natureza: Proteção dos mananciais e exclusão social. São Paulo, Studio Nobel: Editora da Universidade de São Paulo: Fapesp, 1999.

PELLEGRINO, Paulo R. M. Pode-se planejar a paisagem? In: Paisagem e Ambiente: ensaios. N. 13. São Paulo: FAUUSP, dez. 2000.

Paulo R. M.. POR UMA PAISAGEM FLUVIAL PARA A SÃO PAULO. In. PAISAGENS EM DEBATE, revista eletrônica da área Paisagem e Ambiente, FAU. USP - n. 01, outubro de 2003. Disponível em http://www.usp.br/fau/depprojeto/gdpa/paisagens/artigos/2003Paulo-rios.pdf Acesso em 08 jul. 2011.

QUEIROGA, Eugenio Fernandes. A produção da paisagem habitacional metropolitana: três estudos de caso no município de Osasco - SP. Dissertação (mestrado) FAU/USP, São Paulo, 1994.

ROGERS, Richard. Cidades para Um Pequeno Planeta. Tradução de Anita Regina Di Marco, 4플ição. Barcelona: Editorial Gustavo Gili, 2001.

RUANO, M. Ecourbanismo Entornos Humanos Sostenibles: 60 proyecto. AS. Barcelona: Editorial Gustavo Gili, 1999.

SANTOS, Emmanuel Antonio dos. PLANEJAMENTO E PAISAGEM. In. PAISAGENS EM DEBATE, revista eletrônica da área Paisagem e Ambiente, FAU. USP - n. 02, setembro de 2004. Disponível em <http://www.usp.br/fau/depprojeto/gdpa/paisagens/artigos/2004Emmanuelplanejamento.pdf>Acesso em 08 jul. 2011.

SOUZA, Marcelo José L. Mudar a cidade: uma introdução crítica ao planejamento e à gestão urbanos. Rio de Janeiro: Bertrand Brasil, 2002. 